\title{
Pancreatobiliary and peripancreatobiliary tuberculosis: a rare cause of obstructive jaundice
}

Zhenbin Shen, Houbao Liu

Zhongshan Hospital of Fudan University, Shanghai, China

Submitted: 8 October 2010

Accepted: 3 July 2011

Arch Med Sci 2013; 9, 6: 1152-1157

DOI: 10.5114/aoms.2013.39799

Copyright @ 2013 Termedia \& Banach

Tuberculosis (TB) is one of the most common and well-described infectious diseases, with a worldwide distribution and a vast spectrum of clinical manifestations. Tuberculosis involvement of the bile duct, pancreatic, periportal and/or peripancreatic lymph nodes is, however, surprising rare [1]. Patients with TB of the bile duct, pancreatic, periportal and/or peripancreatic lymph nodes usually present with protracted illness and obstructive jaundice, which may be confused with cholangiocarcinoma or pancreatic malignancies.

During a 13-year period we encountered 6 patients with TB of the bile duct, pancreatic, periportal and/or peripancreatic lymph nodes. We describe our experience with the management of this condition and emphasize the importance of a tissue diagnosis in all patients with obstructive jaundice to avoid missing this rare but curable disease, which can elude diagnosis and might prove to be potentially fatal if left untreated.

Records of all patients with obstructive jaundice treated in the Department of General Surgery, Zhongshan Hospital, Medical School of Fudan University between January 1995 and January 2008 were retrieved and reviewed retrospectively, to find patients with a histologically proven diagnosis of TB of the bile duct, pancreatic, periportal and/or peripancreatic lymph nodes. Demographic details, presentation, clinic and radiologic findings, endoscopic and surgical treatment, complications, and follow-up were recorded. Written informed consent was obtained from all patients or patients' relatives, and this study was approved by the local ethical committees.

During the above-mentioned period, of a total of 1400 patients treated for various types of obstructive jaundice in our department, there were $6(0.43 \%)$ patients with TB of the bile duct, pancreatic, periportal and/or peripancreatic lymph nodes.

There were 4 males and 2 females with a mean age of 41.3 (range: $24-$ 54 years). These patients were symptomatic for a mean duration of 2 weeks (range 1 week to 4 weeks). The main presenting symptoms were: jaundice $(n=6)$; epigastric (upper abdominal) pain $(n=4)$; anorexia and weight loss $(n=3)$; fever $(n=4)$ (Table I). All patients were previously healthy and none gave a history of any recent or past contact with tuberculosis. Two patients had a history of alcohol abuse while one was a known diabetic.

Chest radiographs were normal in 5 patients and one patient with pulmonary TB. Human immunodeficiency virus status was negative in all patients. The mean total serum bilirubin level was raised at $192 \mu \mathrm{mol} / \mathrm{l}$ (range: 89-253 $\mu \mathrm{mol} / \mathrm{l}$; normal: 2-24 $\mu \mathrm{mol} / \mathrm{l})$. The mean serum alkaline phosphatase, $\gamma$-glutamyl transpeptidase, and alanine transaminase levels

\author{
Corresponding author: \\ Dr Houbao Liu \\ Zhongshan Hospital \\ of Fudan University \\ No. 180, Fenglinqiao Rd \\ 200032 Shanghai, China \\ Phone: +86-21-64041990 \\ E-mail: \\ drhoubao.liu@gmail.com
}


were as follows: alkaline phosphatase, $490 \mathrm{IU} / \mathrm{I}$ (range: 160-980 IU/l; normal: 30-85 IU/l); $\gamma$-glutamyl transpeptidase, $278 \mathrm{IU} / \mathrm{I}$ (range: 105-810 IU/I; normal: 4-30 IU/l); and alanine transaminase, $41 \mathrm{IU} / \mathrm{I}$ (range: 24-60 IU//; normal: 0-40 IU/l). The mean hemoglobin level was $11.5 \mathrm{~g} / \mathrm{dl}$ (range: 7.8$14.0 \mathrm{~g} / \mathrm{dl})$, and the erythrocyte sedimentation rate was $85 \mathrm{~mm} / \mathrm{h}$ (range: $10-165 \mathrm{~mm} / \mathrm{h}$ ).

All patients underwent abdominal ultrasonography (US) as the first investigation for obstructive jaundice or epigastric pain. It showed dilation of intrahepatic ducts (IHD) and the common hepatic duct (CHD) in 3 patients (patient 3, 5, and 6), one of them with a mass in the porta hepatis (patient 5), one with a mass in the head of the pancreas (patient 6); dilation of the IHD in 2 patients (patient 1 and 2); and a mass in the peripancreatic area in 1 patient (patient 4).

T-tube cholangiographic examination was done in 2 patients; it showed stricture in the proximal common bile duct (CBD), dilated IHD and CHD, then the stricture disappeared 3 months later after T-tube drainage in patient 2 (Figures $1 \mathrm{~A}, \mathrm{~B}$, and C), and stricture in the distal CBD in patient 3 (Figure 2). Abdominal computed tomography (CT) used to acquire additional diagnostic information was performed in 4 patients. Computed tomography showed IHD dilation in patient 2; a pancreatic head mass with enlarged lymph nodes in patient 4; a mass in the porta hepatis in patient 5; and a mass in the head of the pancreas in patient 6 (Table I). Endoscopic retrograde cholangiopancreatography (ERCP) was attempted in patient 5, to define the site and extent of the bile duct obstruction. Endoscopic retrograde cholangiopancreatography showed stricture in the proximal CBD (Figure 3) Magnetic resonance cholangiopancreatography (MRCP) was done in patient 2 during the follow-up, 12 months after T-tube drainage. Magnetic resonance cholangiopancreatography showed that the bile duct obstruction disappeared (Figure $1 \mathrm{D}$ ).

A surgical intervention was done based on the working diagnosis, including hepatectomy, excision of quadrate lobe, and Roux-en-Y hepaticojejunostomy $(n=1)$; Roux-en-Y choledochojejunostomy $(n=2)$; Whipple's pancreacticoduodenectomy $(n=1)$; T-tube drainage with frozen section $(n=1)$; and lymph node resection and frozen section $(n=2)$. The diagnosis was confirmed in all patients by histopathological examination. The most consistent histopathological finding in all the patients was the presence of epithelioid cell granuloma with a central area of caseous necrosis. At the periphery multiple ducts are seen with periductal chronic inflammation and fibrosis. There was no morbidity or mortality related to either ERCP or surgery. All patients received antitubercular therapy (ATT) in the form of isoniazid + rifampicin + pyrazinamide

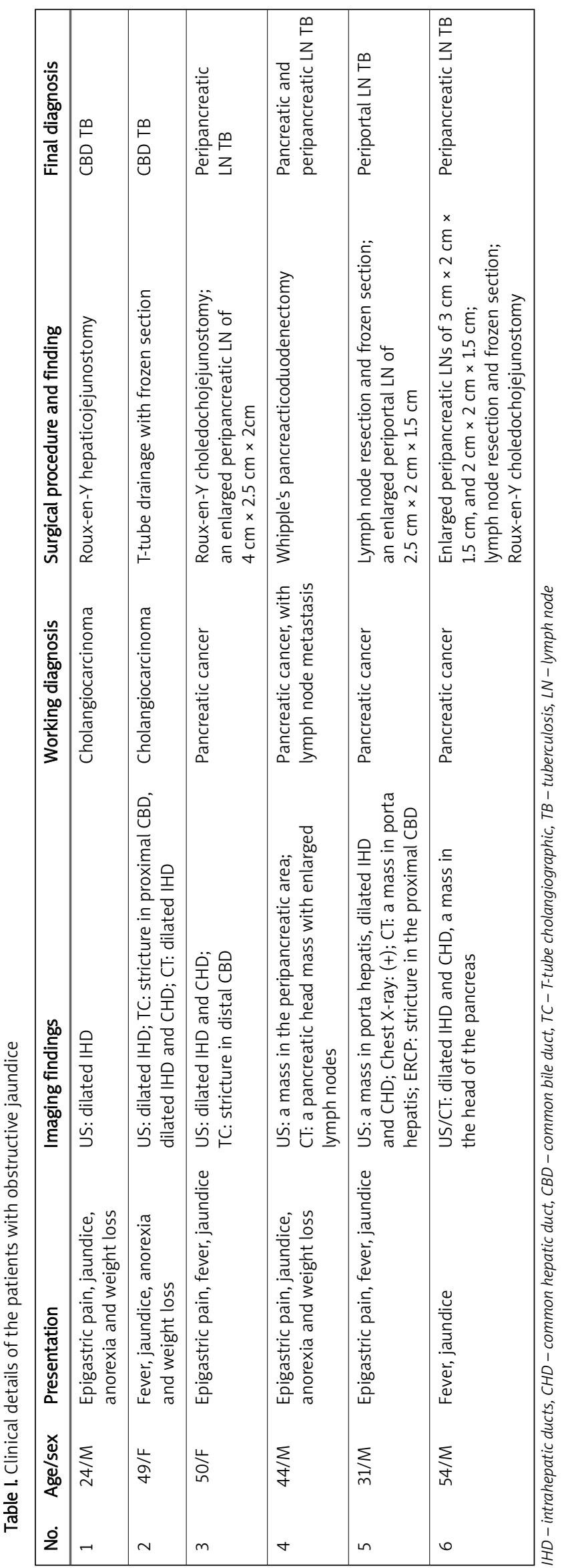



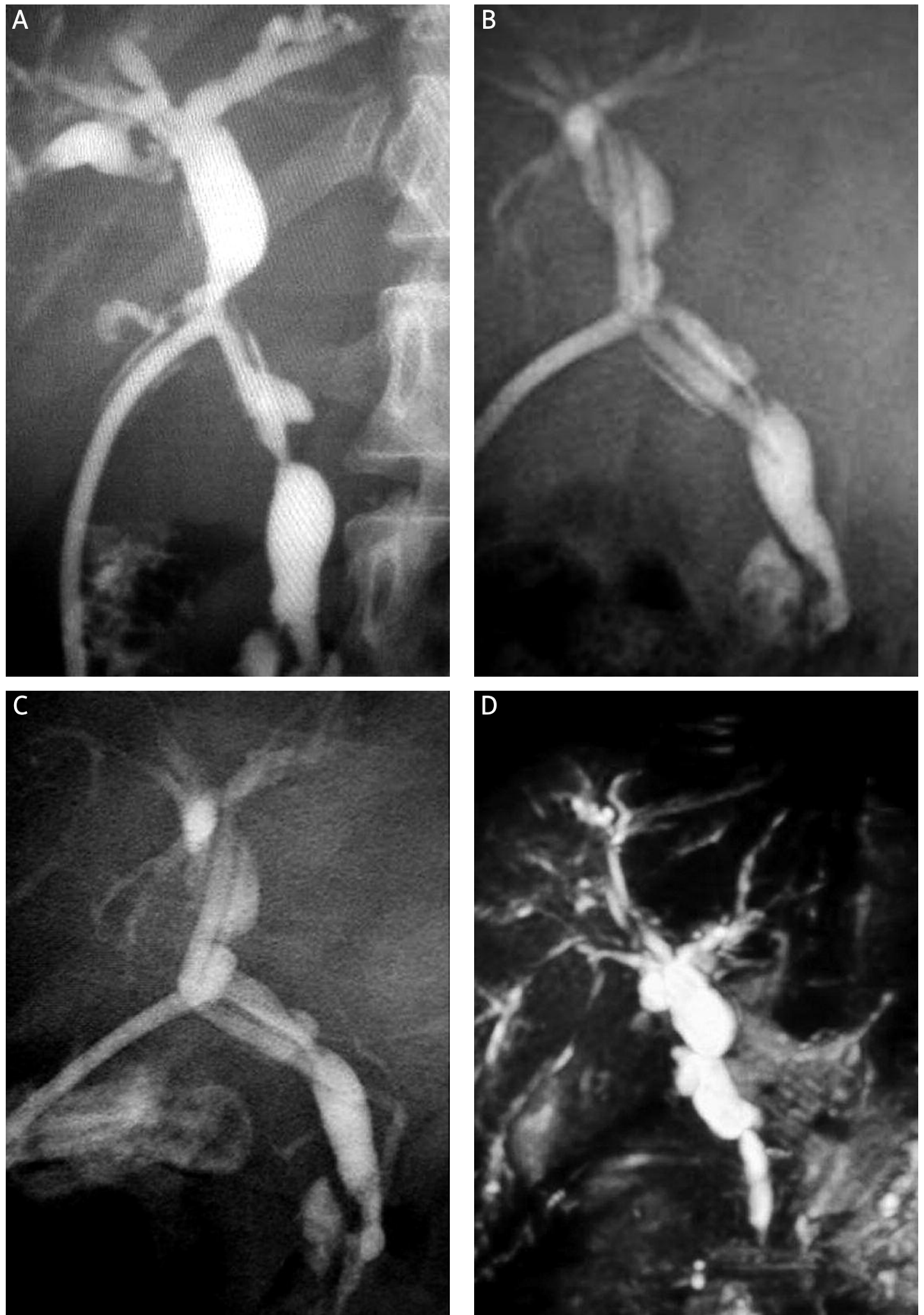

Figure 1. A 49-year-old woman presented with obstructive jaundice. A - T-tube cholangiographic examination was done 1 week after T-tube drainage, and showed stricture in the proximal CBD, dilated IHD and CHD; B, C - T-tube cholangiographic examination was done 3 months and 6 months later, respectively, and showed that the stricture disappeared after T-tube drainage; D - magnetic resonance cholangiopancreatography (MRCP) was done 12 months later, and showed that the bile duct obstruction had disappeared 


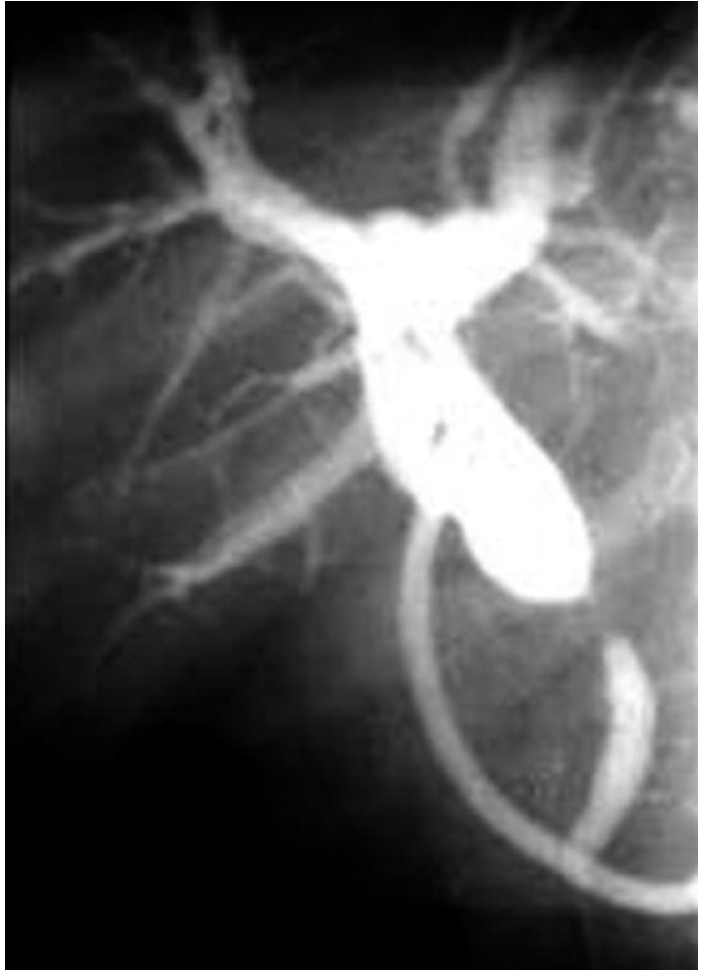

Figure 2. A 50-year-old woman presented with obstructive jaundice. T-tube cholangiographic examination was done and showed stricture in the distal CBD

+ ethambutol for 3 months followed by isoniazid + rifampicin for a further 6 months postoperatively. The mean follow-up of all patients was 40 months (range: 3-72 months). All patients remained healthy with no evidence of jaundice.

In regions with high prevalence of pulmonary TB, abdominal TB is not uncommon. Its prevalence in developing countries has been estimated to be as high as $12 \%$ [2]. Although abdominal TB is thought to be frequently associated with active pulmonary TB, evidence of active pulmonary TB has been reported to occur in 6-38\% of cases [3]. Only 1 of our

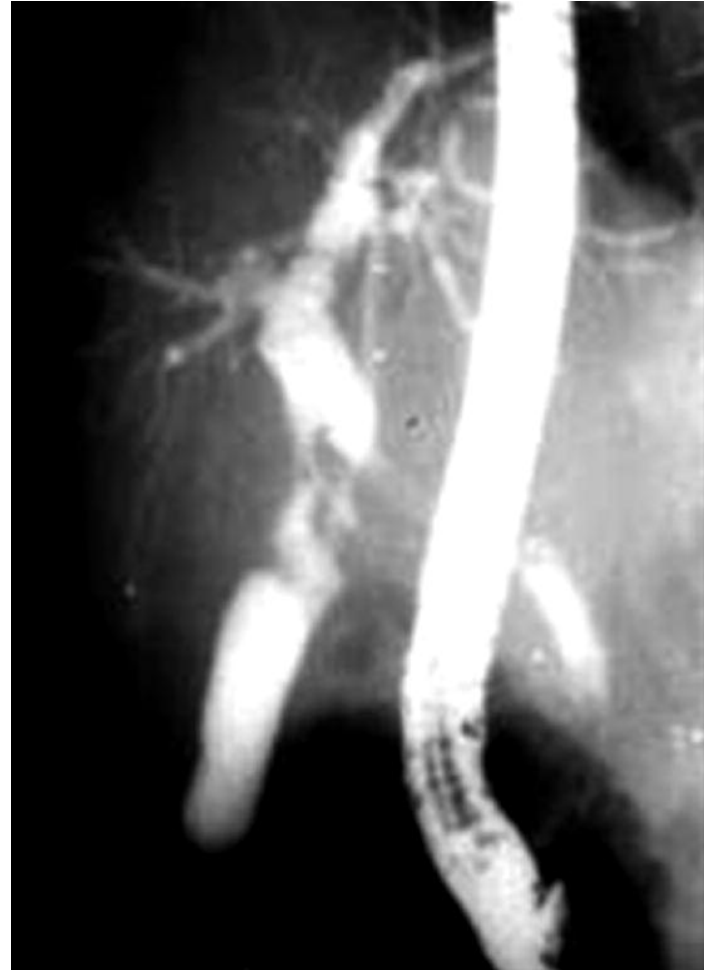

Figure 3. A 31-year-old man presented with obstructive jaundice. Endoscopic retrograde cholangiopancreatography (ERCP) was attempted to define the site and extent of the bile duct obstruction, and showed stricture in the proximal common bile duct (CBD)

patients had evidence of pulmonary TB. Abdominal TB is distinct from pulmonary tuberculosis in that it affects young adults more commonly [4], and is due to the hematogenous route [5], or ingestion rather than inhalation of the pathogen. Following ingestion the bacilli gain access to the gastrointestinal (GI) tract, where necrotizing granulomas may develop and then spread to the lymphatics, affecting any organ in the GI tract, including hepatobiliary and pancreatic tissue [6].

The great majority of bile duct strictures presenting in obstructive jaundice are caused by malig-
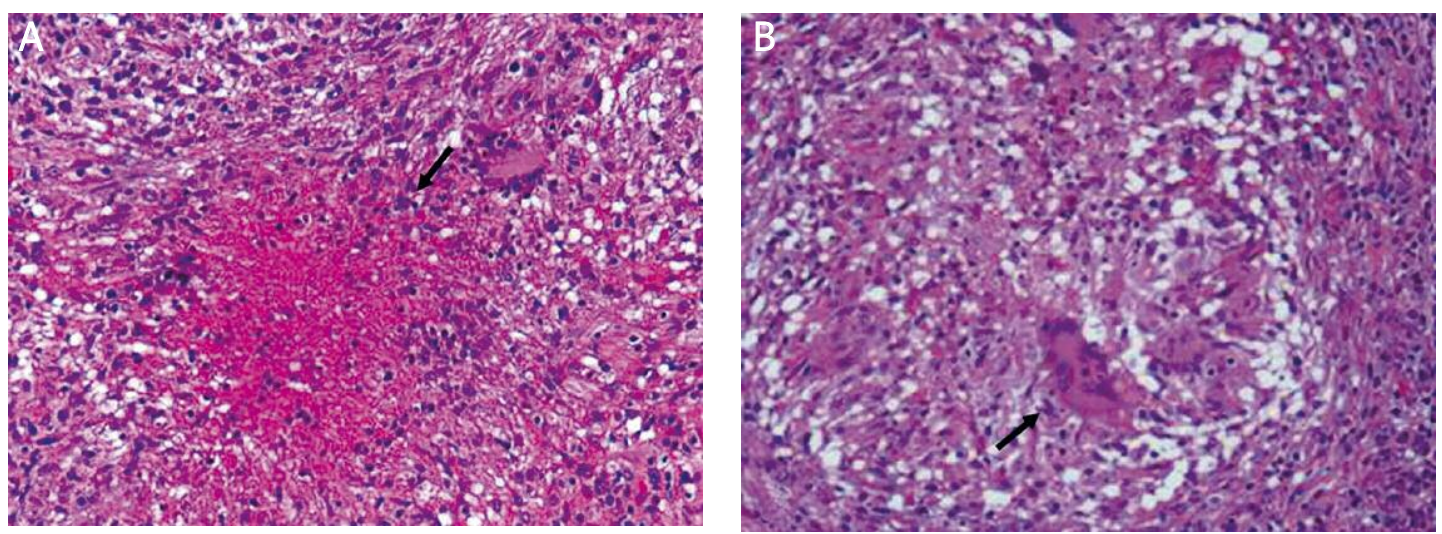

Figure 4. A - Histopathology sections examined under low power (40x) show epithelioid cell granuloma with a central area of caseous necrosis (black arrow). At the periphery multiple ducts are seen with periductal chronic inflammation and fibrosis. B - Sections examined under high power (200x) show ducts with dense chronic inflammatory infiltrates composed of lymphocytes along with periductal fibrosis (black arrow) 
nancies. Benign strictures are usually iatrogenic, often secondary to surgery, radiation, or chemotherapy. Obstructive jaundice secondary to abdominal TB is extremely rare. Four mechanisms have been described: TB of the pancreas itself may cause pseudoneoplastic obstructive jaundice [2, 7-15], as in patient 4 of our cases; it may be secondary to TB lymphadenitis causing compression and inflammation of the lymph nodes and the CBD [11, 16-25], as in patient 3, 5 and 6 of our cases; biliary TB itself may lead to single or multiple strictures, mimicking cholangiocarcinoma [26-30], as in patient 1 and 2 of our cases; and TB can create a retroperitoneal mass leading to biliary tree obstruction [31].

The clinical presentation of hepatobiliary and pancreatic TB is slow and insidious, with non-specific symptoms and signs. In a large review of 300 patients with abdominal TB from India, men and women developed the disease with equal frequency, and although pain was the most common presentation, the symptomatology was variable and nonspecific [32]. In our patients too, abdominal pain (epigastric pain) was the most common presentation $(n=4)$ associated with non-specific symptoms such as weight loss and/or fever. Hepatic TB can occur in miliary, nodular and solitary abscess form [33, 34]. A series from the Philippines [35] showed that patients with hepatic TB presented with fever, abdominal pain and hepatomegaly and both patients in this series had similar complaints. In addition 1 patient presented with melena, which is a rare manifestation. Symptomatic biliary tract TB mimics a primary bile duct or gallbladder cancer or even primary sclerosing cholangitis $[5,26,36]$. In this study, of the 2 patients with biliary tract TB, the working diagnosis was cholangiocarcinoma. Xia et al. found in a series of 16 patients with pancreatic TB that abdominal pain (75\%), anorexia/weight loss (69\%), malaise/weakness (64\%), fever (50\%) and jaundice (31\%) were the common symptoms [11]. These patients mimic carcinoma pancreas or focal pancreatitis [37]. Three of our patients with pancreatic or peripancreatic lymph node TB had abdominal pain $(n=2)$ as the most common manifestation and the working diagnosis was all pancreatic cancer before surgery.

Imaging modalities such as ultrasonography and CT may be useful in demonstrating the dilated bile ducts, and extensive calcification of the liver may be observed. Defining the extent of the bile duct obstruction usually requires cholangiography, either by ERCP or by percutaneous transhepatic cholangiography. The diagnosis of TB of the bile duct is rarely suspected clinically and is often confused with cholangiocarcinoma. In view of the nonspecific presentations and imaging appearance of the disease, a high index of suspicion is required, and definitive diagnosis rates with histologic or bacteriologic evidence of TB. Ultrasonography or CT-guided percutaneous fine needle aspiration (FNA) of the enlarged lymph nodes may be useful [12], but is often not definitive [32]. Cytology of CBD aspirate obtained by ERCP may be confirmatory in the presence of the acid-fast bacillus (Mycobacterium tuberculosis); alternatively PCR of the aspirate may be diagnostic [24]. In the case of a periportal lymphadenopathy causing obstructive jaundice, FNA tests are only positive if a fistula exists between the TB lymph node and the CBD, allowing bacilli to pass into the CBD [24]. Other potential diagnostic methods include obtaining tissue specimens by laparoscopy [22] or endoscopic ultrasound with FNA [38]. However, in practice the diagnosis is often established at operation [11, 12, 23, 31] or even after surgery by histology [9] or PCR-based assay $[2,9,11,13,15]$, as were the cases in this study. Fluorodeoxyglucose-positron emission tomography scanning has not been shown to be useful in distinguishing TB from pancreatic malignancy, as both conditions have an increased uptake of the FDG metabolite [23].

In patients with abdominal TB, once the diagnosis is established, ATT will cure the disease in nearly all patients. However, patients with evidence of biliary obstruction would need either endoscopic or surgical intervention to relieve the obstruction as the ductal narrowing might persist despite treatment with ATT [1, 26, 39-41]. Most (83.3\%) of our patients required a surgical intervention because the preoperative diagnosis was not TB but malignancy. Even though TB lymphadenitis was suspected in patient 6 of our series after intra-operative frozen section, resection of the involved part of the CBD was necessary as the bile duct was already strictured. Thus inexplicable stenosis of the CBD should be taken into consideration in the context of pancreatic or TB lymphadenitis associated with obstructive jaundice and treated by biliary bypass surgery [12] in addition to anti-TB medication, as in patient 1, 3, and 6 of our series. The results of surgery in these patients were satisfactory with no postoperative mortality and low morbidity.

In conclusion, a high index of suspicion in patients with bile duct strictures presenting in obstructive jaundice should prompt vigorous attempts at obtaining a preoperative histological or bacteriological diagnosis. In those with no definite diagnosis preoperatively tissue for frozen section should be obtained. However, in those in whom neither a preoperative nor an intraoperative diagnosis of tuberculosis can be made, a surgical excision may be required. This is usually associated with low morbidity and mortality and good long-term outcome after adequate ATT.

\section{References}

1. Mathew J, Raj M, Dutta T, Badhe B, Sahoo R, Venkatesan M. Extra-pulmonary tuberculosis presenting as obstructive jaundice. Arch Med Sci 2007; 3: 73-5. 
2. Chen $\mathrm{CH}$, Yang CC, Yeh YH, Yang JC, Chou DA. Pancreatic tuberculosis with obstructive jaundice: a case report. Am J Gastroenterol 1999; 94: 2534-6.

3. Hulnick DH, Megibow AJ, Naidich DP, Hilton S, Cho KC, Balthazar EJ. Abdominal tuberculosis: CT evaluation. Radiology 1985; 157: 199-204.

4. Aston NO, Chir M. Abdominal tuberculosis. World J Surg 1997; 24: 492-9.

5. Saluja SS, Ray S, Pal Set al. Hepatobiliary and pancreatic tuberculosis: a two decade experience. BMC Surg 2007; 7: 10.

6. Sinan T, Sheikh M, Ramadan S, Sahwney S, Behbehani A. CT features in abdominal tuberculosis: 20 years experience. BMC Med Imaging 2002; 2: 3.

7. Crowson MC, Perry M, Burden E. Tuberculosis of the pancreas: a rare cause of obstructive jaundice. $\mathrm{Br}$ J Surg 1984; 71: 239.

8. Shan YS, Sy ED, Lin PW. Surgical resection of isolated pancreatic tuberculosis presenting as obstructive jaundice. Pancreas 2000; 21: 100-1.

9. Kouraklis G, Glinavou A, Karayiannakis A, Karatzas G. Primary tuberculosis of the pancreas mimicking a pancreatic tumor. Int J Pancreatol 2001; 29: 151-3.

10. Huang T, Kar S, Javle M. Personalized therapy for pancreatic cancer: myth or reality in 2010? J Gastrointest Oncol 2010; 1: 24-33.

11. Perkins CL, El-Reyes B, Simon E, et al. Single-fraction image-guided extracranial radiosurgery for recurrent and metastatic abdominal and pelvic cancers: shortterm local control, metabolic response, and toxicity. J Gastrointest Oncol 2010; 1: 16-23.

12. El Mansari O, Tajdine MT, Mikou I, Janati MI. Pancreatic tuberculosis. Report of two cases. Gastroenterol Clin Biol 2003; 27: 548-50.

13. Panzuto F, D'Amato A, Laghi A, et al. Abdominal tuberculosis with pancreatic involvement: a case report. Dig Liver Dis 2003; 35: 283-7.

14. Kumar R, Kapoor D, Singh J, Kumar N. Isolated tuberculosis of the pancreas: a report of two cases and review of the literature. Trop Gastroenterol 2003; 24: 76-8.

15. Beaulieu S, Chouillard E, Petit-Jean B, Vitte RL, Eugene C. Pancreatic tuberculosis: a rare cause of pseudoneoplastic obstructive jaundice. Gastroenterol Clin Biol 2004; 28 : 295-8.

16. Kohen MD, Altman KA. Jaundice due to a rare cause: tuberculous lymphadenitis. Am J Gastroenterol 1973; 59: 48-53.

17. Murphy TF, Gray GF. Biliary tract obstruction due to tuberculous adenitis. Am J Med 1980; 68: 452-4.

18. Stanley JH, Yantis PL, Marsh WH. Periportal tuberculous adenitis: a rare cause of obstructive jaundice. Gastrointest Radiol 1984; 9: 227-9.

19. Mathieu D, Ladeb MF, Guigui B, Rousseau M, Vasile N. Periportal tuberculous adenitis: CT features. Radiology 1986; 161: 713-5.

20. Alvarez SZ, Sollano JD Jr. ERCP in hepatobiliary tuberculosis. Gastrointest Endosc 1998; 47: 100-4.

21. Queralt CB, Cruz JM, Comet V Jr, Almajano C, Val-Carreres $C$. Obstructive jaundice due to peripancreatic tuberculous adenitis. Rev Esp Enferm Dig 1992; 82: 201-2.

22. Poon RT, Lo CM, Fan ST. Diagnosis and management of biliary obstruction due to periportal tuberculous adenitis. Hepatogastroenterology 2001; 48: 1585-7.

23. Obama K, Kanai M, Taki Y, Nakamoto Y, Takabayashi A. Tuberculous lymphadenitis as a cause of obstructive jaundice: report of a case. Surg Today 2003; 33: 229-31.
24. Probst A, Schmidbaur W, Jechart G, et al. Obstructive jaundice in AIDS: diagnosis of biliary tuberculosis by ERCP. Gastrointest Endosc 2004; 60: 145-8.

25. Colovic R, Grubor N, Jesic R, et al. Tuberculous lymphadenitis as a cause of obstructive jaundice: a case report and literature review. World J Gastroenterol 2008; 14: 3098-100.

26. Ucar E, Tozkoparan E, Gumus S, et al. Lung parenchymal involvement and sputum bacteriology in tuberculous pelurisy: correlation with pleural fluid biochemical parameters. Arch Med Sci 2009; 5: 450-5.

27. Behera A, Kochhar R, Dhavan S, Aggarwal S, Singh K. Isolated common bile duct tuberculosis mimicking malignant obstruction. Am J Gastroenterol 1997; 92: 2122-3.

28. Yeh TS, Chen NH, Jan YY, Hwang TL, Jeng LB, Chen MF. Obstructive jaundice caused by biliary tuberculosis: spectrum of the diagnosis and management. Gastrointest Endosc 1999; 50: 105-8.

29. Inal M, Aksungur E, Akgül E, Demirba O, Oğuz M, Erkoçak E. Biliary tuberculosis mimicking cholangiocarcinoma: treatment with metallic biliary endoprothesis. Am J Gastroenterol 2000; 95: 1069-71.

30. Prasad A, Pandey KK. Tuberculous biliary strictures: uncommon cause of obstructive jaundice. Australas Radiol 2001; 45: 365-8

31. Jazet IM, Perk L, De Roos A, Bolk JH, Arend SM. Obstructive jaundice and hematemesis: two cases with unusual presentations of intra-abdominal tuberculosis. Eur J Intern Med 2004; 15: 259-61.

32. Bhansali SK. Abdominal tuberculosis experiences with 300 cases. Am J Gastroenterol 1977; 67: 324-37.

33. Chien RN, Lin PY, Liaw YF. Hepatic tuberculosis comparison of miliary and local forms. Infection 1995; 23: 5-8.

34. Achem SR, Kolts BE, Grisnik J, MacMath T, Monteiro CB, Goldstein J. Pseudotumoral hepatic tuberculosis: atypical presentation and comprehensive review of literature. J Clin Gastroenterol 1992; 14: 72-7.

35. Alvarez SZ. Hepatobiliary tuberculosis. J Gastroenterol Hepatol 1998; 13: 833-9.

36. Bearer EA, Savides JT, McCutchan JA. Endoscopic diagnosis and management of hepatobiliary tuberculosis. Am J Gastroenterol 1996; 91: 2602-4.

37. Fischer G, Spengler U, Neubrand M, Sauerbruch T. Isolated tuberculosis of the pancreas masquerading as a pancreatic mass. Am J Gastroenterol 1995; 90: 2227-30.

38. Woodfield JC, Windsor JA, Godfrey CC, Orr DA, Officer NM. Diagnosis and management of isolated pancreatic tuberculosis: recent experience and literature review. ANZ J Surg 2004; 74: 368-71.

39. Ben RJ, Young T, Lee HS. Hepatobiliary tuberculosis presenting as a gallbladder tumour. Scand J Infect Dis 1995; 27: 415-7.

40. Chaudhary A, Negi SS, Sachdev AK, Gondal R. Pancreatic tuberculosis: still a histopathological diagnosis. Dig Surg 2002; 19: 389-92.

41. Iwai T, Kida M, Kida Y, Shikama N, Shibuya A, Saigenji K. Biliary tuberculosis causing cicatricial stenosis after oral anti-tuberculosis therapy. World J Gastroenterol 2006; 12: 4914-7. 